\title{
STUDI KELAYAKAN PELUANG PENGEMBANGAN WISATA RELIGI CANDI PURWO DI TAMAN NASIONAL ALAS PURWO
}

\author{
Rudi Tri Handoko', Jemi Cahya Adi Wijaya² \\ Politeknik Negeri Banyuwangi \\ rudirafif@poliwangi.ac.id, jemiadiwijaya356@gmail.com
}

\begin{abstract}
Abstrak
Peningkatan kunjungan wisatawan yang sangat signifikan setiap tahunnya terjadi di beberapa daya tarik wisata alam yang sudah terkenal di Banyuwangi, diantaranya adalah Destinasi Wisata Taman Nasional Alas Purwo. Selain itu di dalam Kawasan Taman Nasional Alas Purwo ada daya tarik lain yang tak kalah menarik dengan wisata-wisata lain yang ada di Taman National Alas Purwo, wisata tersebut yaitu Candi Purwo. Dengan melihat tingginya potensi wisata tersebut, maka sebagai kegiatan ekonomi yang tak kunjung padam, kegiatan sektor pariwisata dipastikan akan selalu tumbuh dan berkembang. Selanjutnya pertumbuhan dan perkembangan tersebut sebaiknya dapat dikelola dengan baik melalui penerapan manajemen yang baik, untuk itu diperlukan sebuah penelitian untuk melihat sejauh mana peluang wisata religi candi purwo dapat melakukan pengembangan demi kemakmuran masyarakat lokalnya.

Penelitian ini merupakan penelitian kualitatif. Metode yang digunakan dalam pengambilan data dengan cara wawancara. Data yang dipergunakan dalam penelitian ini adalah data primer dan data sekunder. Hasil dari penelitian ini yaitu dari aspek non finansial yang terdiri dari pemanfaatan masyarakat lokal, pelestarian budaya dan pemasaran menunjukkan suatu kelayakan, sehingga dari aspek non finansial candi purwo dapat dijadikan sebagai destinasi wisata baru meskipun ada beberapa hal yang harus dibenahi.
\end{abstract}

Kata Kunci : Destinasi Wisata, Candi Purwo, Potensi Wisata, Aspek Non Finansial, Daya Tarik Wisata Alam

\begin{abstract}
Visitation to tourist destinations in Banyuwangi has increaced significantly every year. One of those destinations is alas purwo national park. Moreover there is an interesting atraction exist in alas purwo national park that is Purwo temple. Looking at that potential, can be predicted as an activity that economic and tourism activities will always grow and develop. For the next, the growing and development of those tourism sector should be well maintained through a good management. So, a research needs to be done to know the potenstial possesedd by religious tourism to support the economy of surrounding community.

This is a qualitative research. The method used to collect the data was interview. The data gathered were primary and secondary data. The result of this research showed that non financial aspect that consist of the use of local community, culture preservation and marketing have a properness. So finansial aspect of Purwo temple can be made as a new tourist destination eventhough there are some aspect that need to be developed.
\end{abstract}

Keywords : Tourism Destinations, Purwo Temple, Tourism Potential, Non-Financial Aspects, Nature Tourism Attractions.

\section{PENDAHULUAN}

Perkembangan pariwisata di Indonesia dapat terlihat dari semakin banyaknya destinasi wisata yang muncul, hal ini tidak terlepas dari diberlakukannya Undang-undang No. 22 Tahun 1999 Tentang Pemerintah Daerah yang memberikan kebebasan dan kewenangan kepada daerah untuk mengatur dan 
memanfaatkan sumber daya yang dimiliki dengan maksimal untuk menghasilkan pendapatan bagi daerah dan memperkenalkan potensi yang dimiliki oleh suatu daerah. Sistem otonomi daerah membuat beberapa daerah di Indonesia mulai mengoptimalkan potensi pariwisata yang dimilikinya, salah satunya adalah Kabupaten Banyuwangi. Pemerintah Daerah Banyuwangi mengandalkan sektor pariwisata untuk meningkatkan pendapatan daerah. Sasaran Dinas Kebudayaan dan Pariwisata Kabupaten Banyuwangi, adalah hasil nyata yang akan dicapai meningkatkan pengembangan obyek wisata yang berbasis pada potensi sumberdaya alam. Dalam berwisata sudah tentu wisatawan tersebut ingin dilayani serta mendapatkan akomodasi yang layak sesuai dengan apa yang diharapkan wisatawan masingmasing (Anggayana \& Sari, 2018).

Dalam kurun waktu empat tahun terakhir, pariwisata Banyuwangi mengalami perkembangan yang signifikan. Banyak potensi wisata baru yang dikembangkan untuk dikenalkan kepada masyarakat. Hal itu tidak lepas dari ide kreatif Pemeritah Kabupaten Banyuwangi untuk memanfaatkan secara maksimal potensi wisata Banyuwangi yang tentunya akan bisa menambah pendapatan asli daerah Kabupaten Banyuwangi itu sendiri. Banyaknya potensi wisata yang di promosikan Banyuwangi berdampak pada meningkatnya jumlah kunjungan wisatawan dari tahun ke tahun.

Peningkatan kunjungan wisatawan yang sangat signifikan setiap tahunnya terjadi di beberapa daya tarik wisata alam yang sudah terkenal di Banyuwangi, diantaranya adalah Destinasi Wisata Taman Nasional Alas Purwo. Kawasan Taman Nasional Alas Purwo memiliki beberapa destinasi wisata yang bisa dikunjungi oleh wisatawan yaitu wisata Sadengan, Pantai Trianggulasri, Pantai Pancur dan G-land. Peningkatan ini sudah tentu ditunjang oleh pelayanan yang baik, dalam pelayanan tersebut, fasilitas dan kualitas pelayanan menjadi ujung tombak dalam hal pemberian kesan baik terhadap pelayanan (Anggayana \& Sari, 2018). Sehingga pendidikan yang berkualitas diperlukan untuk menghasilkan sumber daya manusia yang berkompeten dan mampu bersaing (Anggayani \& Osin, 2018). Sejalan dengan sumber daya manusia diperlukan penguasaan bahasa Inggris, English exist as a global language, therefore English is widely regarded as global language (Anggayana, Nitiasih, \& Budasi, 2016). English is used in the early stages of major social and economic transition (Anggayana, Nitiasih, \& Budasi, 2016). Selain itu di dalam Kawasan Taman Nasional Alas Purwo ada daya tarik lain yang tak kalah menarik dengan atraksi wisata lain yang ada di Taman National Alas Purwo, wisata tersebut yaitu Candi Purwo.

Berdasarkan uraian latar belakang yang telah dikemukakan, maka perlu dilakukan penelitian tentang tingkat kelayakan peluang pengembangan wisata religi candi purwo di taman nasional alas purwo kabupaten banyuwangi. Adapun masalah-masalah yang dianggap perlu untuk dikaji antara lain:

1. Bagaimana Kelayakan Candi Purwo sebagai destinasi pariwisata baru dari aspek non finansial pemanfaatan bagi masyarakat lokal?

2. Bagaimana Kelayakan Candi Purwo sebagai destinasi pariwisata baru dari aspek non finansial pelestarian budaya?

3. Bagaimana Kelayakan Candi Purwo sebagai destinasi pariwisata baru dari aspek non finansial pemasaran?

\section{METODE}

Data yang dipergunakan dalam penelitian ini adalah data primer dan data sekunder yang didapatkan dari Badan Perencanaan Pembangunan Daerah (Bappeda) Banyuwangi, Dinas Pariwisata kab. Banyuwangi, Kantor Desa Kedungasri Kec. Tegaldlimo Banyuwangi, dan wawancara kepada pihak-pihak yang terlibat dalam pengembangan objek wisata religi ini. Data-data yang dibutuhkan mencakup kajian pengembangan objek wisata religi Candi Purwo Desa Kedungasri dari Bappeda Banyuwangi, data kunjungan wisatawan di kab. Banyuwangi dari Dinas 
Pariwisata Banyuwangi. Data lain yang mendukung penelitian ini diperoleh dari tulisan ilmiah, makalah, jurnal, atau sumber-sumber lain yang relevan

Data yang diperoleh dalam penelitian ini adalah data primer dan data sekunder. Data primer yaitu data yang diperoleh langsung dari sumbernya sedangkan data sekunder merupakan data yang telah tersedia. Dalam penelitian ini data primer diperoleh langsung dari lokasi penelitian melalui dua metode:

1. Wawancara

Moleong (2014) adalah sebuah kegiatan percakapan dengan maksud tertentu dan dilakukan oleh kedua pihak, yaitu pewawancara (interviewer) yang mengajukan pertanyaan dan terwawancara (interviewee) yang memberikan jawaban pertanyaan yang diajukan. Wawancara adalah proses tanya-jawab dalam penelitian yang berlangsung secara lisan. Teknik wawancara banyak digunakan di Indonesia sebab merupakan salah satu bagian yang terpenting dalam setiap penelitian. Menurut prosedurnya wawancara dapat dibedakan menjadi 3 yaitu, wawancara bebas (wawancara tak terpimpin), wawancara terpimpin, wawancara bebas terpimpin.

2. Dokumentasi

Sukardi (2009) untuk memperoleh data dari responden adalah menggunakan teknik dokumentasi. Pada teknik ini, peneliti dimungkinkan memperoleh informasi dari bermacam-macam sumber tertulis atau dokumen yang ada pada responden atau tempat, di mana responden bertempat tinggal atau melakukan kegiatan sehari-harinya.

\section{HASIL DAN PEMBAHASAN}

\section{Pemberdayaan Masyarakat Lokal}

Tahapan-tahapan partisipasi masyarakat perlu dikaji didalam pembangunan destinasi pariwisata baru. Sehingga dapat diketahui tahapan partisipasi yang telah dicapai oleh masyarakat di desa Kedungasri Kecamatan Tegaldlimo Kabupaten Banyuwangi dalam mengembangkan wisata Candi Purwo sebagai objek wisata religi. Menurut
Judisseno (2017; 123) mengemukakan ada 8 tahapan dalam partisipasi masyarakat didalam pembangunan pariwisata yaitu manipulation, therapy, informing, consultation, placation, partnership, delegate power, citizen control.

Pada penelitian ini partisipasi masyarakat di Desa Kedungasri Kecamatan Tegaldlimo Kabupaten Banyuwangi dalam pengembangan wisata religi Candi Purwo masuk pada tahapan yang ke tiga yaitu tahap informing. Pada tahapan ini kesadaran masyarakat tentang pentingnya partisipasi mereka dalam pembangunan pariwisata melalui program-program yang ditawarkan oleh pemerintah mulai meningkat. Level ini pemerintah biasanya hanya merekrut beberapa anggota masyarakat yang dianggap mampu dan mengerti tentang konsep pembangunan pariwisata dan dapat menyebarluaskan informasi tersebut kepada masyarakat luas. Menurut Pemangku dari Candi Purwo pihaknya telah melakukan program-program yang berhubungan dengan pariwisata yang dilakukan setiap seminggu sekali seperti diadakan bersih-bersih disekitar Candi Purwo. Selain dijadikan objek wisata juga, fungsi Candi Purwo yang utama juga dijadikan sebagai tempat persembahyang Umat Hindu. Jadi disetiap hari besar Umat Hindu Candi Purwo dipastikan ramai pengunjung.Menurut Anstein dalam Judisseno (2017:126) menamai proses ini dengan tokeinsm, dikarenakan proses ini mengutamakan keterwakilan dari kelompok-kelompok tertentu untuk berpartisipasi dalam pengambilan keputusan.

\section{Pelestarian Budaya}

Pengembangan wisata religi Candi Purwo saat ini sudah berjalan sesuai dengan keinginan masyarakat setempat untuk di jadikan sebagai wisata religi untuk semua umat beragama, akan tetapi pengembangan yang di lakukan tidak berjalan dengan cepat karena keterbatasan dana yang dimiliki. Saat ini wisata Candi Purwo sudah dibangun akses jalan untuk memudahkan masyarakat atau wisatawan datang mengunjungi wisata tersebut. Jalan yang 
dibangun untuk saat ini hanya dapat dilalui oleh pejalan kaki dan sepeda motor saja. Wisata religi Candi Purwo untuk saat ini belum memiliki sarana dan prasaranan yang lengkap seperti belum adanya area parkir, toilet, warung-warung, dan akomodasi. Pengembangan wisata religi Candi Purwo memerlukan adanya dukungan dari Pemerintah khususnya Dinas Kebudaaan dan Pariwisata Kabupaten Banyuwangi untuk pengembangan berkelajutan. Tetapi setidaknya dengan mengetahui ceritanya kita dapat melestarikan cerita tersebut menjadi daya tarik budaya. Menurut Sedarmayanti (2014:15) Kebudayaan merupakan perwujudan kemampuan manusia, menyesuaikan diri dengan lingkungannya menjadi acuan (pedoman) bagi masyarakat dalam melakukan tata pergaulan dalam kehidupan bermasyarakat, berbangsa, dan bernegara.

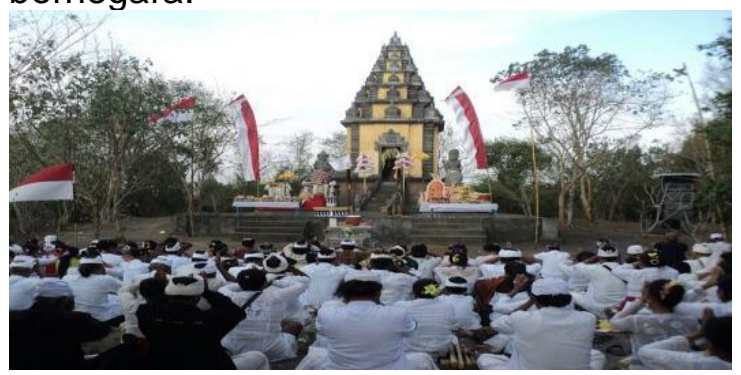

Gambar 1. Pelestarian Budaya

\section{Pemasaran}

Aspek pemasaran pada penelitian ini lebih difokuskan pada segi citra destinasi pariwisata (destination image). Hal tersebut dipilih karena menurut Echtner dkk dalam Utama (2017:219) pada hakikatnya citralah yang sebenarnya menggerakkan dan mendorong wisatawan menentukan pilihan destinasi pariwisatanya. Harapannya dengan menilai citra destinasi pariwisata Candi Purwo dapat diketahui permintaan dan penawarannya sehingga dapat disimpulkan kelayakan Candi Purwo sebagai destinasi pariwisata.

Menurut Beerli dan Martin dalam Utama (2017:223) terdapat sembilan atribut yang mempengaruhi citra destinasi yaitu atribut alamiah (natural resumbers), kesempatan wisatawan untuk bersenang-senang dan rekreasi (tourist leisure and recreation), lingkungan alamiah (natural environment), fasilitas umum (general infrastucture), budaya ; sejarah ; seni (culture,history, art), lingkungan sosial (social environment), infrastruktur pariwisata (tourist infrastructure), faktor ekonomi dan politik (political and economic factor), suasana destinasi (atmosphare of the place). Berdasarkan survey yang dilakukan oleh Pemerintah Kabupaten Banyuwangi tahun 2017 dengan 9 variabel tersebut, indeks tingkat kepuasan wisatawan domestik mencapai nilai 86,7 dengan skala 1-100. Kemudian indeks kepuasan wisatawan mancanegara mencapai nilai 81 dengan skala 1-100. Selanjutnya berdasarkan survey tentang potensi wisatawan yang berkunjung ke Banyuwangi, mereka lebih menyukai jenis wisata bahari dan wisata alam. Kesimpulannya potensi wisata di Kabupaten Banyuwangi akan semakin meningkat di tahun mendatang karena indeks tingkat kepuasan yang sangat baik, terutama para wisatawan yang menyukai wisata alam dan bahari. Berdasarkan data tersebut, potensi wisatawan Candi Purwo di masa mendatang akan meningkat sekalipun masih banyak hal yang harus dibenahi.

\section{PENUTUP}

Kesimpulan penelitian ini adalah sebagai berikut Aspek Non Finansial yang terdiri dari pemanfaatan masyarakat lokal, pelestarian buadaya Candi Purwo, serta pemasaran menunjukkan suatu kelayakan untuk dilanjutkan menjadi suatu destinasi pariwisata. Sekalipun masih banyak hal yang harus di perbaiki.

\section{DAFTAR PUSTAKA}

Anggayana, I. W. A., \& Sari, N. L. K. J. P. (2018). Kemampuan Berbicara Bahasa Inggris Mahasiswa Akomodasi Perhotelan: sebuah Kajian Fonologi. Jurnal Manajemen Pelayanan Hotel, 1(1), 8-14.

ANGGAYANA, I. W. A., NITIASIH, D. P. K., BUDASI, D. I. G., \& APPLIN, M. E. 
D. (2016). Developing English For Specific Purposes Course Materials for Art Shop Attendants and Street Vendors. Jurnal Pendidikan Bahasa Inggris Indonesia, 4(1).

Anggayani, N. W., \& Osin, R. F. (2018). Pengaruh Service Performance Terhadap Nilai Sekolah Kepuasan Dan Loyalitas Pelajar Pada Smk Pariwisata Triatma Jaya Tabanan. Jurnal Manajemen Pelayanan Hotel, 1(1), 2835.

Dinas Kebudayaan dan Pariwisata. 2017. Data Kunjungan Wisatawan dan Obyek Daya Tarik Wisata Tahun 2010-2016. Banyuwangi (ID): Dispar.

Fatimah S. 2015. Strategi Pengembangan Obyek Daya Tarik Wisata Religi (Studi Kasus di makam Mbah Mudzakir Sayung Demak) [skripsi]. Semarang (ID): Universitas Islam Negeri Walisongo Semarang.

Fandeli, Chafid. 2000. Pengertian dan Konsep Dasar Ekowisata. http://www.saveforest.webs.com/konse $\mathrm{p}$ ekowisata.pdf (diakses 22 Januari 2014).

Irfani, Rofiq. 2011. Analisis Kelayakan Pengembangan Usaha Ransel Laptp di UMKM Yogi Tas Desa Laladon Kecamatan Ciomas Kabupaten Bogor. Bogor : Institut Pertanian Bogor.
Judisseno, Rimsky K. 2017. Aktivitas dan Kompleksitas Kepariwisataan. Jakarta : Kompas Gramedia.

Nadiasa Mayun, D. N. K. Widnyana Maya, I. N. Norken. 2010. Analisis Investasi Pengembangan Potensi Pariwisata Pada Pembangunan Waduk Jehem di Kabupaten Bangli. Jurnal IImiah Teknik Sispil Vol. 14 No. 2

Nugroho Iwan. 2009. Pengembangan Ekowisata dalam Pembangunan Daerah.http://iwanuwg.files.wordpress. com/2009/08/ekowisata-bangdarevisi.pdf (diakses 22 Januari 2014).

Pemerintah Republik Indonesia. 1990. Undang-Undang Republik Indonesia No. 9 Tahun 1990 Tentang Kepariwisataan

Sedarmayanti. 2014. Membangun \& Mengembangkan Kebudayaan Industri Pariwisata. Bandung: Refika Aditama.

Supatra K. 2012. Candi Purwo: Jejak Nusantara. Denpasar (ID): Universitas Udayana

Syarif, Kasman. 2011. Analisis Kelayakan Usaha Produk Minyak Aromatik Merek Flosh (Studi Kasus Pada UKM Marun Aromaterapi). Bogor : Institut Pertanian Bogor.

Utama, I Gusti Bagus Rai. 2017. Pemasaran Pariwisata. Yogyakarta: Andi. 